Zapata, Olar.

Artista, profesor-investigador, Universidad Autónoma Metropolitana unidad Azcapotzalco, División de Ciencias y Artes para el Diseño, departamento de Evaluación del Diseño en el Tiempo, Área de Semiótica.

\title{
Máscaras de lucha libre mexicana para ver la ciudad virtual con nuevos imaginarios urbanos.
}

\author{
TIPO DE TRABAJO \\ Comunicación. \\ PALABRAS CLAVE \\ Máscaras, Rostro, Imaginarios, Ciudad, Derivas.
}

KEY WORDS

Masks, Face, Imaginary City, Drifts.

\section{RESUMEN}

Me interesa la ciudad desde la perspectiva virtual que se genera a través de la imaginación y que empapa de fantasías nuestra vida urbana.

Este proyecto artístico pone en el centro del análisis la influencia del rostro en la conformación de identidad y a su vez la modificación de la percepción de la ciudad y la recomposición de los imaginarios urbanos con la utilización de máscaras de lucha libre mexicana. Siguiendo a Deleuze y su concepto de rostridad, se encuentra la influencia del rostro en las relaciones humanas y los cambios de percepción urbanos, que generan formas diferentes de tránsito y apropiaciones del espacio. En este proyecto el rostro se entiende como una máscara permanente.

Siguiendo las ideas de Armando Silva, Daniel Hiernaux y Néstor García Canclini entre otras personas el término "imaginarios urbanos" nada en el terreno de lo intangible, de la idea, de la representación y la imaginación, pone en primer lugar la experiencia que genera en las personas el espacio urbano, vuelca su atención en lo sensible, en las imágenes mentales que vemos cuando cerramos los ojos.

A nivel práctico se han realizado varias exploraciones urbanas a manera de derivas experimentales con la utilización de máscaras de lucha libre utilizadas como operadores espaciales. Las máscaras de lucha son utilizadas para disolver los significados del rostro (pigmentocracia, género, edad, defectos físicos, estado de ánimo, etc.) y su influencia en la percepción virtual de la ciudad. Las derivas nos ayudan a repensar las identidades normalizadas, cambiarlas, cambiar los imaginarios urbanos y con ellos el comportamiento como transeúnte para apropiarnos y transformar los significados de la ciudad vivida.

Actualmente este proyecto ha tocado ciudades cómo Tuxtla, Ciudad de México, Buenos Aires, Berlin, Praga, Lisboa, Valencia, Paiporta, Tarragona, Madrid, Barcelona, Paris, Venecia, Roma, y San José Costa Rica.

\section{ABSTRACT}

I am interested in the city from the virtual perspective it is created through imagination and fantasy that permeates our urban life.

This art project puts at the center of analysis the influence of the face in shaping identity and in turn changing the perception of the city and the rebuilding of urban imaginary with the use of Mexican wrestling masks. Following Deleuze 
and faciality concept, is the influence of face human relationships and changes in urban perception, different ways of generating traffic and appropriations of space. In this project the face is seen as a permanent mask.

Following the ideas of Armando Silva, Daniel Hiernaux and Néstor García Canclini among others the term "urban imaginary" nothing in the realm of the intangible, the idea of representation and imagination, puts experience first generated in people urban space, turns his attention to the sensible, in the mental images we see when we close our eyes.

On a practical level there have been several urban explorations by way of experimental drifts with the use of wrestling masks used as spatial operators. Wrestling masks are used to dissolve the meanings of the face (pigmentocracy, gender, age, physical defects, mood, etc.) and their influence on the virtual perception of the city. Drifts help us rethink and change the standard identities, change the urban imaginary and with them as a transient behavior to appropriate and transform the meanings of the city lived.

This project has now touched cities how Tuxtla, Mexico City, Buenos Aires, Berlin, Prague, Lisbon, Valencia, Paiporta, Tarragona, Madrid, Barcelona, Paris, Venice, Rome and San Jose Costa Rica.

\section{CONTENIDO}

\section{Introducción}

Cada que caminamos por la ciudad nuestros ojos miran la vida urbana, vemos las calles, vemos los autos, los edificios, las casa, los centros comerciales o a otras personas, hay también muchas otras cosas que no vemos pero que sin embargo dibujan nuestra experiencia en la ciudad. Como si viviéramos en otro mundo virtual, esas cosas que no vemos con los ojos son producto de la imaginación, que en un contexto citadino toma nombre de imaginario urbano, y en este como comenta Armando Silva "puede aceptarse que en la percepción de la ciudad hay un proceso de selección y reconocimiento que va construyendo este objeto simbólico llamado ciudad; y que en todo símbolo o simbolismo subsiste un componente imaginario. Este procedimiento corresponde a un recorrido similar aceptado, según modernas aproximaciones para cualquier reconstrucción lógica de las manifestaciones concebidas como <<inconscientes〉>" (1 pág. 97). La ciudad que vivimos cotidianamente se dá en gran parte por la ciudad imaginada que almacenamos en el inconsciente. Esta ciudad imaginada nos potenciará o desechará la percepción de la seguridad, las caracteristicas culturales, los lugares de esparcimiento, la percepción de tranquilidad o la sensación de arraigo entre otras congeturas que elaboramos sobre las zonas urbanas que conocemos o desconocemos en la urbe. Al imaginar la ciudad, también nos imaginamos en ella, y construimos una ilusión de como debemos de utilizarla, transitarla, disfrutarla y vivirla, en suma, el imaginario urbano nos hace tomar una actitud ante la ciudad basada en nustras fantasias.

Otra cosa que no vemos al caminar por las calles de la ciudad es nuestro rostro, salvo que de manera esporádica nos crucemos con algún espejo y aprovechemos para revisar nuestro peinado o si el maquillaje aún está intacto, en los demás momentos del día nuestro rostro es invisible, pero siempre está presente en nuestra memoria y comportamientos, es parte fundamental para la constante elaboración de imaginarios urbanos. Como comenta Erving Goffman (2) hemos aprendido a ser actores y actrices de un papel impuesto por estructuras identitarias que muchas veces adaptamos de manera inconsciente, Judit Butler (3) con su teoría de los actos performativos años después refuerza esta idea. Así pues si nuestro rostro es leído socialmente como el rostro de una mujer poco atractiva, seguramente esa carga significante influirá en el papel que representamos como persona, si hemos nacido con un color de piel de color negro intenso, seguramente nuestro rostro desprenderá significados hacia quién nos mire que serán diferentes de los que se desprenderían si nuestro rostro tibiera un color de piel blanca y una textura tersa.

El rostro es protagonista de nuestra persona, y si vivimos en una sociedad a la que le encanta engrandecer los protagonismos, entonces nuestro rostro será nuestra más valorable carta de presentación. Pensemos por un momento en la gran cantidad de películas de ficción que tienen como protagonista a un héroe o heroína, si vemos los carteles publicitarios de esas películas nos daremos cuenta que la gran mayoría toman el rostro de los personajes como un elemento central del mensaje visual, pensemos en las grandes revistas de la farándula como la revista "Caras" siempre hay rostros en las portadas, el protagonismo focaliza la atención en personas individuales, los artistas más famosos del mundo firman sus obras como individuos, sus rostros se conocen por todo el mundo, también los países son presididos por una presidenta o un presidente, no dos ni tres, sus retratos aparecen en miles de oficinas de gobierno, el protagonismo centraliza, puntualiza y focaliza la mirada en una persona destacada, nos hace creer que lo correcto es la superación personal y que es verdad que el sistema funciona, pues quién más se esfuerza es quién más beneficios tiene como individuo. 
El rostro eclipsa muchas veces a la persona y la persona se subordina a los significados del rostro, entonces el rostro en vez de revelar la personalidad, también puede ocultarla, como si ese fuera una máscara. El rostro se hiper-valora y al verlo parece que vemos la verdad de la persona, más sin en cambio solo vemos una cutícula superficial, es como si tratáramos de saber si un aguacate esta bueno solo viendo su cascara, sin sentir si está blando o duro, o sin abrirlo y mirarlo por dentro. Felix Guattari y Gilles Deleuze acuñaron el termino rostridad, que nos dará luz, pues propone que el rostro no es más que una construcción abstracta e ideológica, una capa de piel que envuelve la cabeza como si fuera una capa, en sus palabras "El rostro solo se produce cuando, la cabeza deja de formar parte del cuerpo, cuando deja de estar codificada por el cuerpo" (4 pág. 176). El rostro bajo la idea de la rostridad traslada su significado a todo el cuerpo, entonces el cuerpo se rostrifica, el rostro entonces es el gran repartidor de significado, puede representar a una persona por sí solo, una fotografía de carnet en automático nos habla de una persona en particular, en cambio una fotografía de que encuadra todo un cuerpo excepto el rostro, nos puede generar dudas sobre su identidad.

El protagonismo y sus rostros deslumbrantes se tambalean cuando entra a escena el anonimato, pues esté diluye la atención a una sola persona, pues al no saber su identidad, podría ser cualquiera. El anonimato se puede dar de múltiples maneras, desde la generación de un falso perfil de Facebook hasta la organización de un grupo de hackers que operan sin dejar rastro de su autoría como anonymous. El anonimato también se da con una simple acción, cubrirse el rostro. No necesitamos cubrir todo nuestro cuerpo, si solamente cubrimos el rostro el anonimato aparece, pues el rostro como hemos visto, es la parte del cuerpo que más nos caracteriza, al disolverla nos volvemos no-protagonistas así que podemos ser cualquier persona. Esto me interesa, pues genera cortos circuitos a la ideología dominante que gusta por tener todo y a todas las personas identificables.

Cubrir el rostro para generar anonimato puede hacerse de infinidad de maneras, muestra de ello es echar un vistazo a las diferentes culturas que han poblado la tierra desde hace miles de años, en la gran mayoría se ha generado máscaras que se utilizaron y se utilizan en bailes, danzas o actos rituales, en la historia del arte la máscara también ha tenido un papel importante, recordemos a las Guerrilla Girls, el trabajo de Orlan, las acciones de la Pocha Nostra, las fotografías de Lionel Bayol-Thémines, Oweena Fogarty o el teatro griego. Desde mi posición parcial y situada según la teoría de Donna Haraway (5), me interesa cubrir el rostro con máscaras de lucha libre mexicana, pues para mi historia personal han sido de suma importancia desde que era un niño, grandes fantasías he construido con los personajes de la lucha libre a lo largo de mi vida, por otro lado a nivel social, este tipo de máscaras han logrado arropar una gran carga cultural que representa parte de la cultura mexicana. La máscara de lucha libre corre el riesgo de ser un elemento estereotipado con respecto a la identidad mexicana, así como el sombrero de charro o el picante en la comida, puede generar convenciones ficticias sobre una identidad que es más diversa y cambiante que ermitica y estable como representan estos clichés identitarios. Al generar anonimato con máscaras de lucha libre y utilizarlas como objeto artístico, su significado cambia, sus convenciones se descomponen y la identidad asociada a ella se transforma cual si fuera un engendro, cosa que me resulta fascinante.

En vez de utilizar las máscaras de lucha libre para representar un personaje y combatir cuerpo a cuerpo arriba de un cuadrilátero, he utilizado las máscaras de lucha como operadores espaciales así como los define Salomón González "El operador espacial es una entidad identificable que participa en la dinámica y en la organización de una acción individual y/o colectiva, que está activa durante un proceso socio-espacial... se basa en la interacción que se establece entre otras entidades y que de algún modo contiene implicaciones espaciales, como: generar distancias, orientar lógicas de localización, organizar lugares, influir sobre flujos de movimientos, filtrar el desplazamiento de otras entidades, establecer barreras, etc." (6 pág. 30). La máscara de lucha como operador espacial modifica nuestro comportamiento en el espacio público de la ciudad.

\section{Desarrollo}

A nivel de práctica artística, desde hace años me interesa desenmascaras los efectos del rostro en nuestro comportamiento y la modificación de imaginarios urbanos, para esto he utilizado máscaras de lucha libre para generar anonimatos colectivos y caminar por diferentes ciudades del mundo a manera de deriva experimental. Tomo el andar a la deriva como un instrumento de investigación urbana y acto estético a la vez, tal y como lo plantea Franscesco Careri (7). La deriva urbana es una de las maneras en las cuales las personas podemos conocer las caras ocultas de la ciudad, es una acción que tiene antecedentes desde comienzos de la humanidad al remitirnos a las comunidades nómadas que en su andar encontraron los asentamientos que hoy son nuestras grandes ciudades. El andar es una forma simbólica de construir nuestra propia ciudad, púes la ciudad es el espacio urbano que recorremos.

En nombrado a esta serie de derivas experimentales "Desenmascarando máscaras humanas". Se realizan en colectivo y comienzan con la selección de una máscara de lucha libre que por un par horas será el sustituto del rostro-máscara que portamos a diario. La máscara de lucha libre se vuelve operador espacial y entonces ocasiona un cambio de comportamiento y de percepción que poco a poco va cambiando el imaginario urbano y la forma de ocupar y transitar la ciudad. Los recorridos tienen un punto de inicio y pero no un punto de finalización, entre todo el grupo que conforma la acción se van tomando decisiones improvisadas para construir la ruta de la deriva.

He realizado este trabajo artístico en Ciudad de México, Tuxtla, Buenos Aires, Berlin, Praga, Lisboa, Valencia, Paiporta, Tarragona, Madrid, Barcelona, Paris, Venecia, Roma, y San José Costa Rica. En este texto detallaré lo sucedido en la ciudad de Tuxtla Gutiérrez Chiapas, México. 


\section{Tuxtla Gutiérrez Chiapas}

La ciudad capital de Chiapas es de terreno muy complicado, sus calles tienen la mala fama de estar plagadas de defectos tanto en aceras como en calles y avenidas, sin embargo su ordenación urbana que toma el parque central como punto cero, hace que la referencia geográfica de las calles de norte a sur y de oriente a poniente sea muy clara para la ubicación espacial. Las derivas experimentales intervinieron en tres zonas urbanas de la ciudad que tienen como punto de unión la avenida central que cruza por todas ellas, empezando en la Facultad de artes de la Universidad de ciencias y Artes de Chiapas, después la zona de la rectoría de la UNICACH, el parque bicentenario y el parque de la marimba, terminando en la zona del parque y avenida 5 de mayo. Cada zona fue distinta, el carácter urbano de la zona limítrofe a la Facultad de Artes de la UNICACH es la menos caminable de las tres, en especial de noche, la zona que rodea a rectoría de UNICACH y el parque de la marimba, tiene un carácter más comercial y cultural, mientras que la zona urbana que envuelve a la Av. 5 de mayo es de carácter más popular con gran diversidad de comercios y servicios.
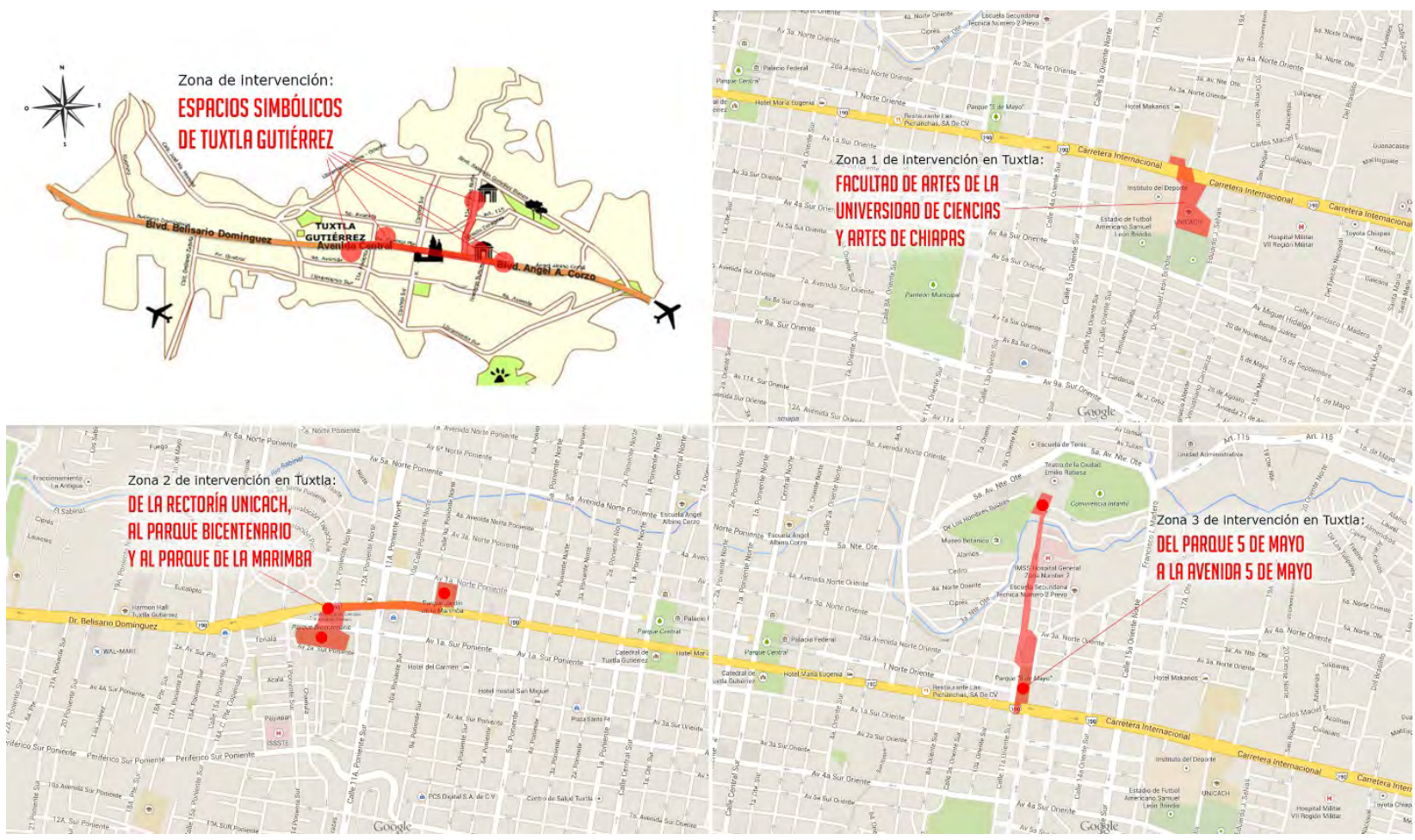

Ubicación en el mapa de Tuxtla - Tuxtla Gutiérrez Chiapas - Olar Zapata - Google Maps 2013
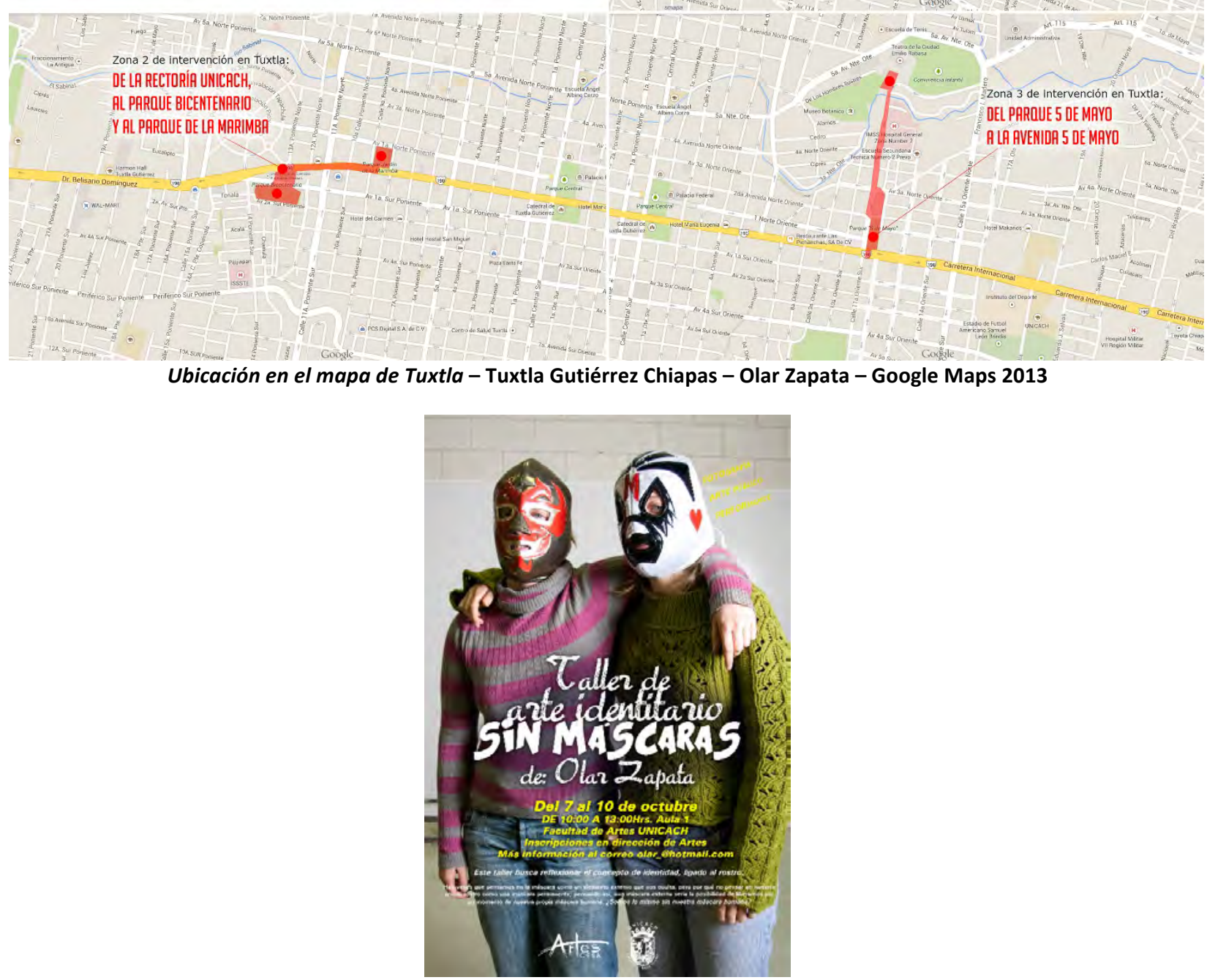

Cartel del taller de arte identitario SIN MÁSCARAS - Tuxtla Gutiérrez Chiapas - Olar Zapata - 2013 
Como parte de una estancia de investigación en la Universidad de Ciencias y Artes de Chiapas, participé impartiendo un taller de arte identitario en el marco del Foro Universitario de las Artes 2013, en el cual vertí parte de la investigación teórico práctica de este proyecto. El formato de taller para comenzar la intervención urbana funcionó de manera muy positiva para el proyecto, durante 4 días reflexionamos grupalmente el tema de la identidad, los imaginarios urbanos, el rostro y el anonimato, el penúltimo día realizamos una intervención al interior de la universidad. Para el último día las personas tenían una idea más clara del significado de su rostro así que nos embarcamos a realizar la deriva experimental en el espacio público de la ciudad de Tuxtla.

Esta deriva experimental fue bastante potente, éramos un grupo de más de 40 personas todas sin rostro humano. Los y las integrantes de la intervención en su mayoría estudiantes de primer semestre de licenciatura, al usar las máscaras de lucha en grupo refirieron sentirse con el control de la situación y del espacio, teniendo la sensación de hacer lo que ellos y ellas quisieran y sin molestias a otras personas, esto se vio muy claro en la manera en la cual intervinieron su universidad, pues con su rostro humano eran vistos como novatos, lo cual les dificultaba la apropiación espacial de las mejores zonas de la escuela, con su rostro desrotrfificado ocuparon cuantas zonas quisieron de la escuela, llegando incluso a introducirse sin problemas a las oficinas de dirección y diferentes talleres y al auditorio central.
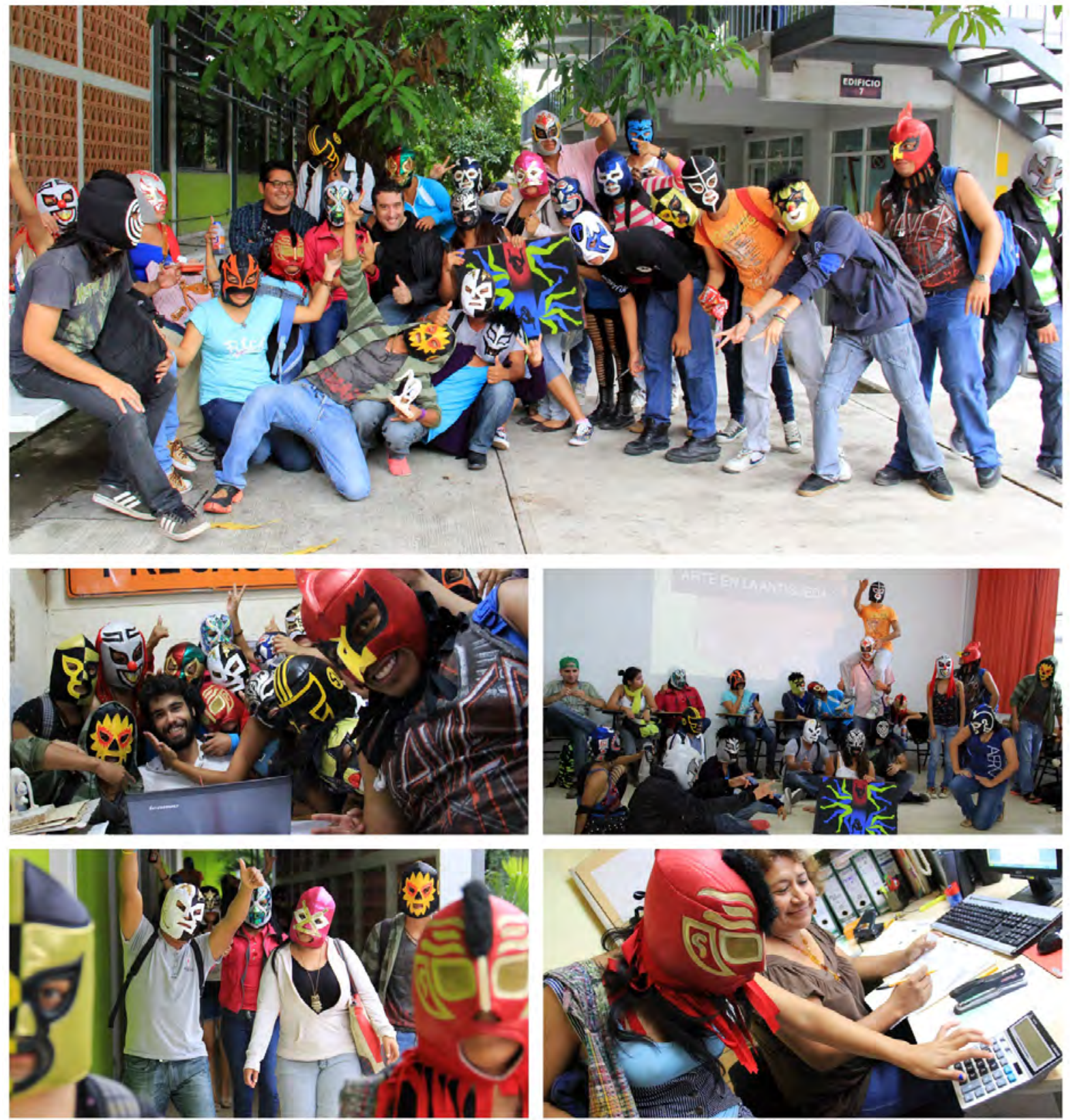

Desenmascarando máscaras humanas - Tuxtla Gutiérrez Chiapas - Olar Zapata - 2013 
Al comenzar la deriva experimental, saliendo de la Facultad de Artes de la UNICACH utilizamos el transporte público generando desde el primer momento una ruptura en el uso convencional del sistema de transporte, la sola presencia colectiva de personas sin rostro confundía a los y las pasajeras, las reacciones iban desde la indiferencia, la sobrada sorpresa o la sonrisa cómplice.
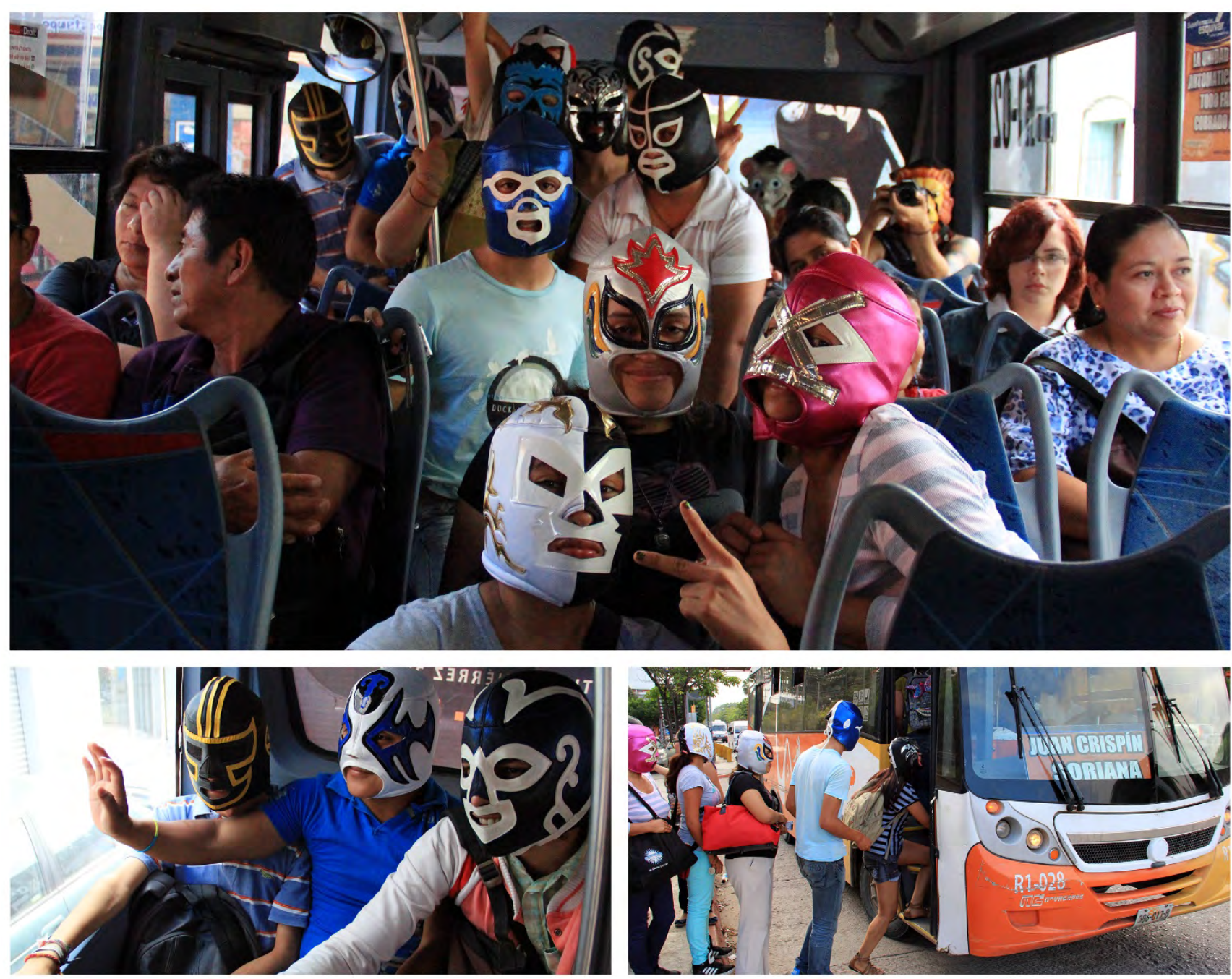

Desenmascarando máscaras humanas - Tuxtla Gutiérrez Chiapas - Olar Zapata - 2013

Nuestra deriva Urbana nos llevó de la Facultad de Artes de la UNICAH, hasta el edificio de Rectoría, el parque bicentenario, el parque de la marimba, la avenida central, el parque 5 de mayo, la avenida 5 de mayo hasta culminar en un balneario público donde acabamos nadando sin quitarnos las máscaras de lucha. Esta intervención generó un impacto fuerte en los participantes, la tendencia a la colectividad y la solidaridad del anonimato se manifestaba con actitudes de compañerismo y confianza, como en el caso del acompañamiento a una chica del grupo que tiene problemas de cadera y solo puede desplazarse con muletas, todo el grupo caminó a su ritmo. 

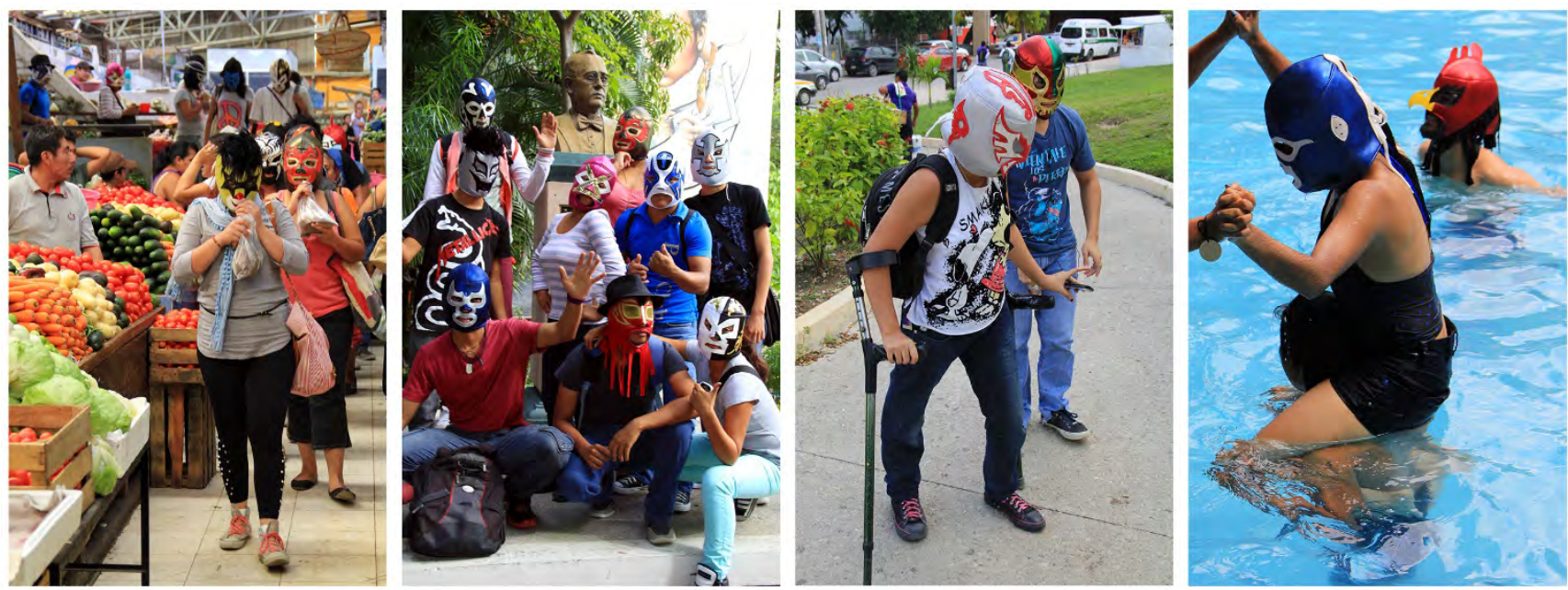

Desenmascarando máscaras humanas - Tuxtla Gutiérrez Chiapas - Olar Zapata - 2013

En algunos momentos de la deriva experimental nos detuvimos para tratar de percibir y ocupar de manera diferente el espacio en el que estábamos, un ejemplo notable fue al llegar al quiosco central del parque de la marimba, lugar donde cada tarde se sitúan agrupaciones de marimba y tocan un par de horas, en una práctica diaria que ya es tradición y se reconoce en todo México y el extranjero. Pedí al colectivo que exploraran otras maneras de ocupar el quiosco, de inmediato y sin ningún pudor las personas comenzaron a recostarse sobre el piso, colgarse y meterse entre los huecos de los barandales, brincar por las escaleras o practicar break dance. El lugar cambio radicalmente, la gente que se encontraba a los alrededores parecía sorprendida, un espacio simbólico de la ciudad, cargado con un fuerte sentido cultural y turístico, se convirtió en laboratorio de unas personas que sacaban partes de su personalidad que no habían sacado durante los días anteriores dentro del salón donde se impartió el taller de arte identitario.
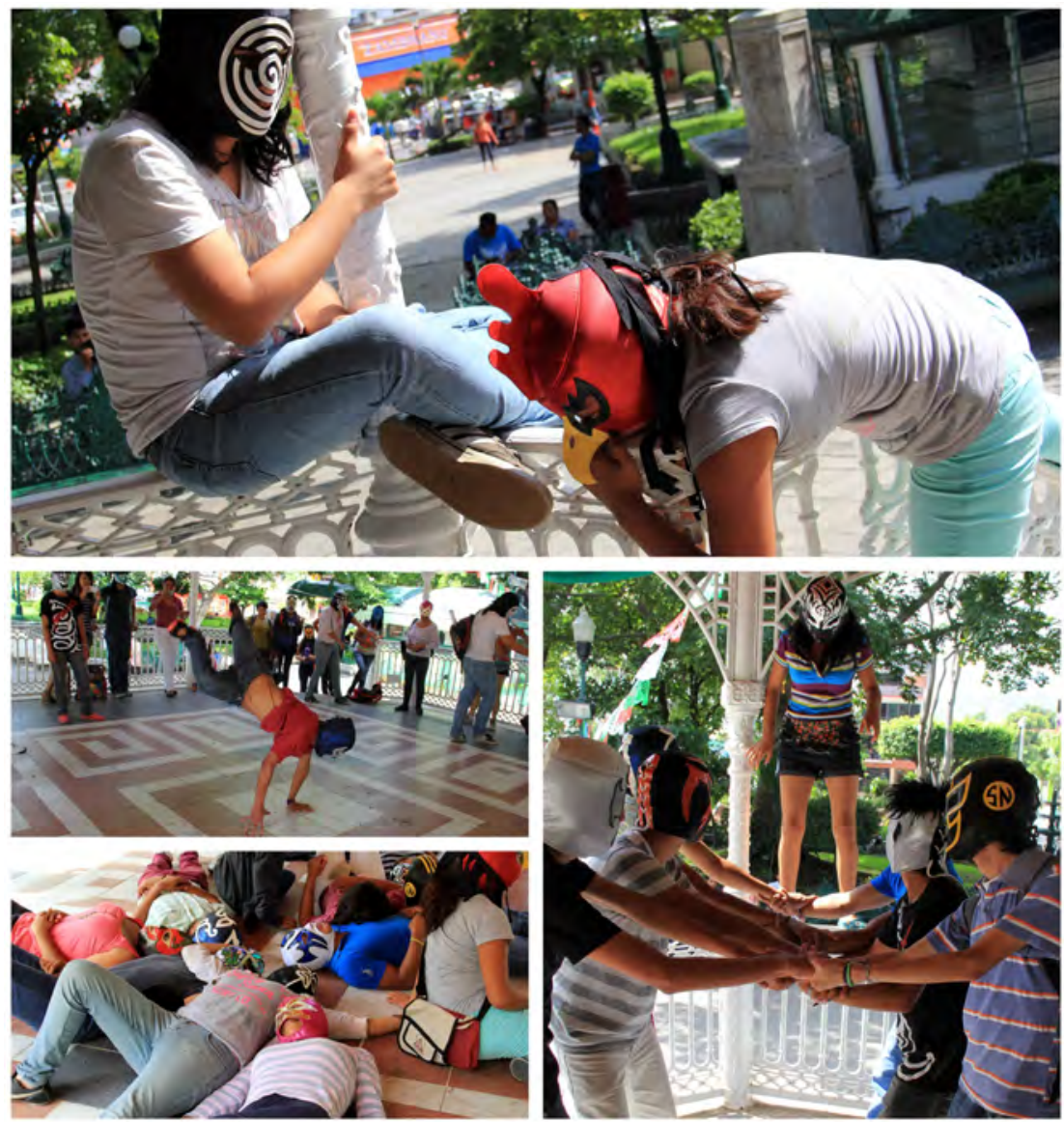

Desenmascarando máscaras humanas - Tuxtla Gutiérrez Chiapas - Olar Zapata - 2013 
Al finalizar la intervención, la sinergia de la colectividad continúo y según comentarios el imaginario de la ciudad se modificó, hubo quién dijo que redescubrió Tuxtla, la ciudad donde había nacido. Las personas, hicieron conscientes los significados del rostro y después de la intervención comentaron no preponderarlos a la hora de darle valor a las personas con las que tienen amistad.

\section{Conclusiones}

Puedo afirmar que el rostro es un elemento que comunica identidad e los imaginarios urbanos, un nodo, un puente que cual fachada de una casa es la puerta de entrada hacia las identidades que nos conforman como personas y la ventana donde se cuela la luz que dibuja la ciudad imaginada que contenemos en nuestras mentes.

El rostro por tanto no es ajeno a la ciudad, el rostro es ciudad, el rostro construye ciudad, la ciudad de los rostros humanos se evidencia cuando los ocultamos y hacemos aparecer la ciudad del anonimato identitario. Nuestro rostro conforma gran parte de nuestra identidad, y nuestra identidad nos hace constituir nuestros imaginarios urbanos, cuando la identidad sufre una ruptura en su constitución al cuestionar los significantes del rostro, se abre una puerta para reconfigurar los imaginarios urbanos.

El rostro en ausencia de reflexión tiene tendencia hacia la individualidad, hacia la reproducción de los valores alienados de las identidades urbanas normativas, el rostro entendido como una marca registrada contamina la solidaridad en beneficio del bien personal, el rostro dentro del entramado urbano dominado por los imaginarios hegemónicos es un artefacto de distinciones, sectorización y discriminación. El rostro en cambio diluido y superado tiene tendencia la colectividad y la solidaridad, el anonimato desestabiliza el sistema individualista, lo saca de quicio, lo confunde, el rostro desrostrificado y cubierto por el manto de la incertidumbre que genera la práctica artística hace atravesar sus vicios para encontrarnos como humanos iguales. La falta de distinción y reconocimiento individual beneficia una actitud solidaria en el espacio urbano, el anonimato detonado por una práctica artística que utiliza la máscara de lucha libre como operador espacial, evidencia el condicionamiento que la ciudad tiene ante el rostro. Se va el rostro y se desactivan muchas estrategias de control imaginario en las ciudades, se va el rostro idea y aparecen los imaginarios emancipados, libres y diversos de la ciudad.

Los imaginaros urbanos no están condenados a permanecer la vida entera en el terreno de lo virtual, son y siempre han sido vehículo para la construcción de la materialidad urbana, no hay elemento tangible en la ciudad que antes no haya pasado por la imaginación y la representación de esta en dibujos o palabras.

\section{FUENTES REFERENCIALES.}

1. Silva, Armando. Imaginarios urbanos. Bogotá : Arango Editores, 2006.

2. Goffman, Erving. La presentación de la persona en la vida cotidiana. Buenos Aires : Amorrortu editores, 1997.

3. Actos performativos y constitución de género: un ensayo sobre fenomenología y teoría feminista. Butler, Judith. México : s.n., 1998, Debate femminista, Vol. 18, págs. 296-314.

4. Deleuze, Gilles y Guattari, Félix. Año cero - rostridad. Mil mesetas. Capitalismo y ezquizofrenia. Valencia : Pretextos, 1997, págs. 173196.

5. Haraway, Donna Jeanne. Ciencia, cyborgs y mujeres. La reinvención de la naturaleza. . Madrid : Ediciones Cátedra, 1995.

6. González Arellano, Salomon. Policentralidad a partir de los patrones viaje-actividad en la ZMVM. [aut. libro] Oscar Terrazas Revilla. La ciudad que hoy es cetro. México D.F. : UAM Azcapotzalco - CONACYT, 2010, pág. 30.

7. Careri, Francesco. Walkscapes El andar como práctica estética. Barcelona : Gustavo Gili, 2013. 